\title{
Failure of Mountain-Anchors as Consequence of Hydrogen Embrittlement
}

\author{
Michael Panzenböck ${ }^{1}$, Caroline Freitag ${ }^{1}$ \\ 1. Department of Physical Metallurgy and Materials Testing, Montanuniversität Leoben, Austria
}

Mountain-anchors are used to stabilize flanks of hills, back slopes, walls of tunnels etc. The aim of such stabilizing elements is to avoid or to reduce geological movements and to protect people, railways, roads, etc. against falling rocks or hillside slumping. Depending on specific geological conditions, the anchors are fixed in the mountain using various techniques, while mounted on a concrete support on the outside. The anchors are pre-stressed for a better stabilization. Consequently, the rods or wires used for such fixing elements, have to withstand very high tension loads over many decades.

During inspection of several hundred mountain-anchors, many of them were found broken. Furthermore, most of them lost nearly completely their pre-stress. The strands were manufactured from seven high strength steel wires in this case.

A macroscopic overview of 6 broken strands is given in Fig. 1. All strands, especially the wires, are covered with soil, lubricant and corrosion products. Fig. 2 shows a strand after disassembly. Each strand consists of 6 wires arranged at the circumference (wires 1-6) and 1 wire located in the center (wire 7). From macroscopic inspections it can be noticed that wires located at the outside show a heavily corroded surface. In addition, the fracture surfaces are inclined to the wire axes (Fig. 2, wires 1-6). In contrast to this, the wire located in the center reveals less corrosion attacks and symmetrically cup and cone fracture (Fig. 2, wire 7).

Metallographic inspections in a longitudinal direction of the wires are shown in Figs. 3a and 3b. Some wires exhibit a very high content of non-metallic inclusions (Fig. 3a). The wires are manufactured from an unalloyed carbon steel with a carbon content of nearly 0.8 wt-\%. Fig. 3 b reveals the microstructure, which consists of a very fine and heavily deformed pearlite structure (Sorbite) with a small amount of ferrite located at grain boundaries. The measured tensile strength ranges from $1780 \mathrm{MPa}$ to $1980 \mathrm{MPa}$, and is influenced by the inclusion content. Metallographic investigations near the fracture surfaces in longitudinal direction reveal many cracks starting from the outside and crack branches (Fig. 4). These features are exclusively present in the wires located at the outside. Scanning electron microscopy (SEM) reveals transgranular fracture as exemplified in Fig. 5. The centered wire shows a ductile fracture behavior.

It is known that high strength steels are susceptible to hydrogen. Therefore, we developed a simple testing method by using a bending equipment in diluted hydrochloric acid. The tested specimens taken from wires revealing the same features as damaged ones (Figs. 4 and 5). From these results we can conclude that the wires failed due to hydrogen induced stress corrosion cracking.

The sequences of damage can be summarized as follows: A damage of the corrosion protection leads to penetration of water and local corrosion. The damage is caused by hydrogen resulting from the corrosion process. Bending stresses and the texture of the microstructure are responsible for crack propagation in nearly longitudinal direction. The continuous damage of the outer wires causes high tensile stress in the center wire, which fails by cup and cone fracture. 


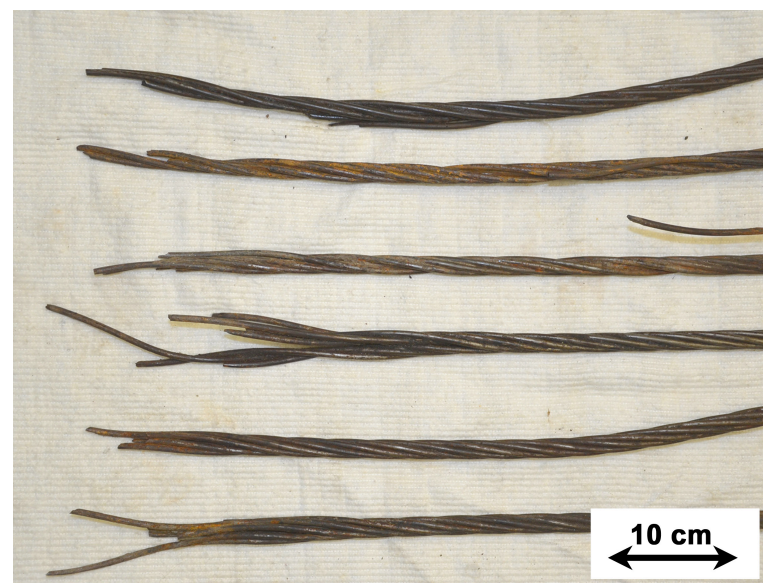

Figure 1. Macroscopic overview of broken mountain-anchors (anchor strands) made from high strength steel wires.

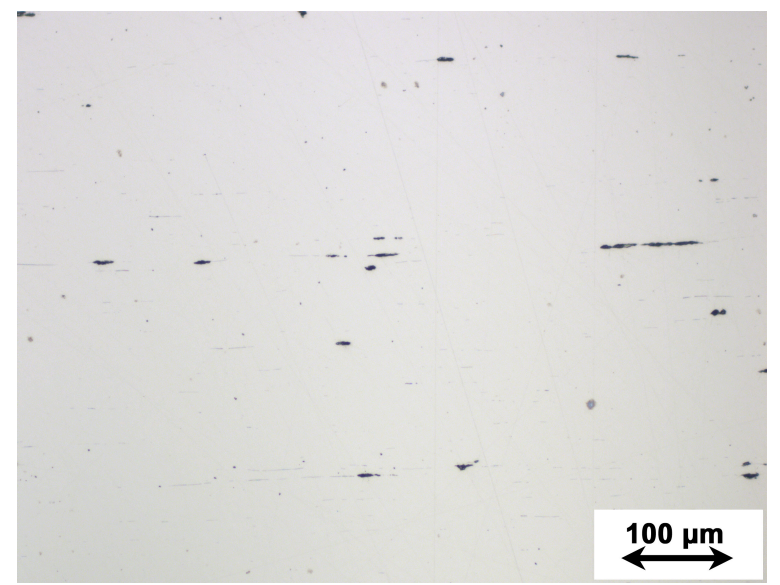

Figure 3a. Light optical micrograph in a longitudinal direction. Many nonmetallic inclusions are visible.

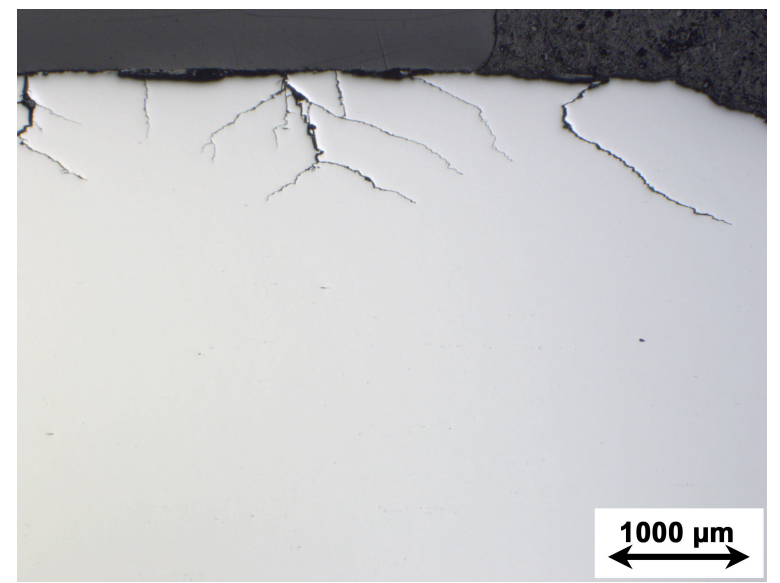

Figure 4. Cracks are initiated at the surface and propagate in the direction of the texture. Many crack branches are visible.

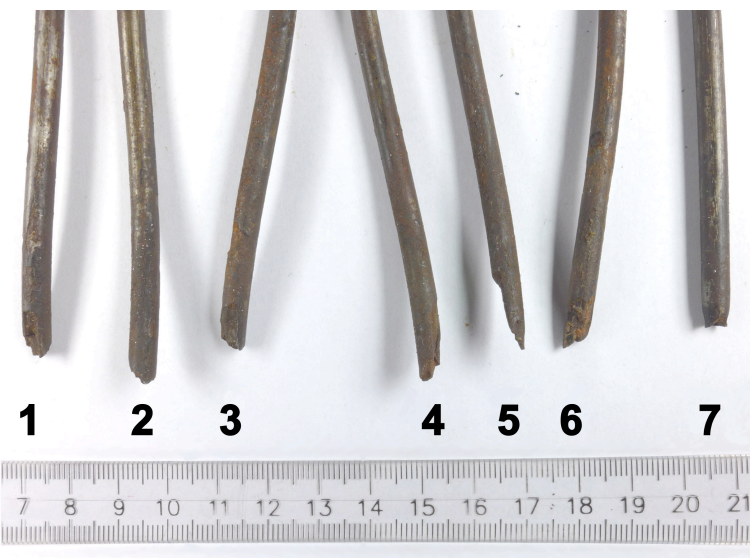

Figure 2. Disassembled strand, wires 1-6 circumferential wires. Wire 7 from the center failed by cup and cone fracture.

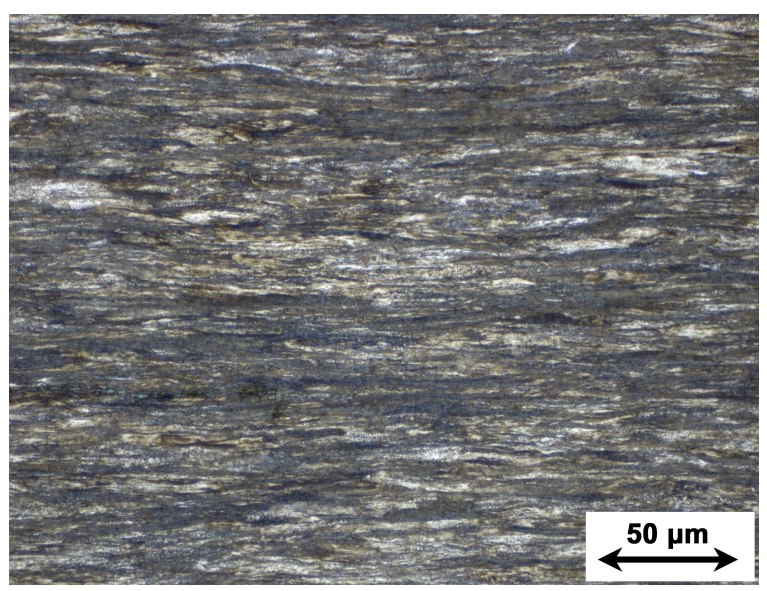

Figure 3b. Light optical micrograph of the microstructure after etching. Sorbite and Ferrite at the grain boundaries are visible.

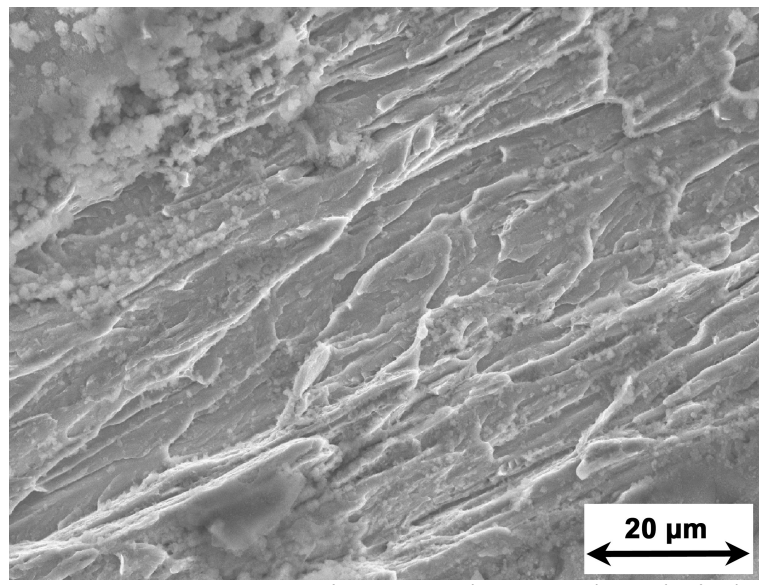

Figure 5. SEM micrograph reveals a brittle fracture surface. Cracks propagate exclusively transgranularly. 